\title{
Studi Kinerja Mesin Pemotong Bambu
}

\author{
Ishak Paneo $^{1)}$, Mustofa $^{2)}$, Siradjuddin Haluti ${ }^{3)}$ \\ 1,2,3) Program Studi Mesin dan Peralatan Pertanian, Politeknik Gorontalo \\ Jl. Muchlis Rahim, Desa Panggulo Barat, Kec. Botupingge, Kab. Bone Bolango, Gorontalo, Indonesia \\ e-mail: fikalpaneo6@gmail.com
}

\begin{abstract}
ABSTRAK
Bambu adalah tanaman jenis rumput-rumputan dengan rongga dan ruas dibatangnya yang setiap tahunnya banyak dimanfaatkan oleh masyarakat Gorontalo. Pemanfaatan bambu tentunya tidak terlepas dari proses pengolahan, terutama pemotongan. Proses ini menuntut adanya peralatan atau mesin yang dapat digunakan untuk keperluan pemotongan dalam skala yang besar. Hal ini karena proses pemotongan bambu di Gorontalo secara umum dilakukan dengan cara manual. Penelitian ini merupakan studi literatur untuk menentukan indikator-indikator yang dapat diterapkan dalam pembuatan mesin pemotong bambu. Dengan demikian akan dihasilkan mesin/alat pemotong bambu yang efisien. Studi litertur pada penelitian ini menggunakan beberapa sumber dari artikel atau jurnal sebagai dasar kajian. Hasil penilitian menunjukkan bahwa penggunaan mesin pemotong bambu dapat meningkatkan produktivitas. Peningkatan produktivitas dapat dilihat dari efisiensi waktu yang digunakan lebih sedikit dibandingkan dengan pemotongan bambu secara manual. Penggunaan mesin pemotong bambu dapat mereduksi waktu kerja sekitar 82-84\%. Untuk memaksimalkan penggunaan mesin pemotong bambu maka perlu adanya modifikasi alat/mesin yang mempertimbangkan beberapa aspek seperti sistem kerja otomatis melalui bantuan software dan sensor, perancangan alat/mesin disesuaikan dengan postur tubuh para pekerja, dan penggunaan penutup mata pisau atau gurinda.
\end{abstract}

Kata Kunci: bambu, mesin pemotong, studi literatur

\begin{abstract}
Bamboo is a type of grass plant with cavities and segments in its trunk which is widely used by the people of Gorontalo every year. The use of bamboo certainly can not be separated from the processing process, especially cutting. This process requires equipment or machines that can be used for large-scale cutting purposes. This is because the bamboo cutting process in Gorontalo is generally done manually. This research is a literature study to determine the indicators that can be applied in the manufacture of bamboo cutting machines. Thus, an efficient bamboo cutting machine/tool will be produced. The literature study in this study used several sources from articles or journals as the basis for the study. The results showed that the use of bamboo cutting machines can increase productivity. The increase in productivity can be seen from the efficiency of the time used is less compared to the manual cutting of bamboo. The use of a bamboo cutting machine can reduce working time by about $82-84 \%$. To maximize the use of bamboo cutting machines, it is necessary to modify tools/machines that consider several aspects such as automatic work systems through the help of software and sensors, design of tools/machines adapted to the posture of the workers, and the use of blade covers or grinders.
\end{abstract}

Keywords: bamboo, cutting machines, literature study 


\section{PENDAHULUAN}

Bambu adalah tanaman jenis rumput-rumputan dengan rongga dan ruas dibatangnya. Di dunia ini bambu merupakan salah satu tanaman dengan pertumbuhan paling cepat. Karena bambu memiliki sistem rizhoma-dependen unik yang memungkinkan dalam sehari bambu dapat tumbuh sepanjang $60 \mathrm{~cm}$ (24 inchi) bahkan lebih, tergantung pada kondisi tanah dan klimatologi tempat ia ditanam. Disamping itu, bambu merupakan salah satu hasil bumi di Indonesia yang dapat dimanfaatkan secara meluas untuk memenuhi berbagai keperluan manusia.

Ribuan jenis bambu telah diidentifikasi di dunia. Sebanyak kurang lebih 1250 jenis bambu dan $11 \%$ dari jumlah jenis bambu merupakan hasil sumber daya alam yang ada di Idonesia. Bambu memiliki beberapa karaktersitik seperti tekstur yang kuat, fleksibel, dan permukaan kulit yang bervariasi coraknya (Handayani, 2009). Ketersediaan bambu di Indonesia belum sepenuhnya memiliki nilai jual karena kesadaran masyarakat yang masih rendah akan pengolahanya dan pemanfaatannya (Sulastiningsih, 2008). Beberapa hasil olahan bambu dapat dimanfaatkan untuk bahan bangunan rumah, interior rumah, alat pertanian, alat makan, tusuk sate, sangkar burung, bahkan digunakan untuk media karya para seniman (Jana, 2007; Arhamsyah, 2009).

Selain itu, bambu merupakan salah satu jenis material/bahan yang bisa dijadikan sebagai pengganti kayu (Widyaningrum, dkk., 2019), dimana semakin meningkatnya pemanfaatan kayu sehingga persediaan semakin berkurang. Oleh karena itu, bambu mejadi salah satu solusi sebagai bahan baku untuk idustri pengolahan kayu di Indonesia. Hal ini karena sumber daya bambu di Indonesia cukup potensial. Hampir di setiap daerah di Indonesia dijumpai tanaman bambu, baik di pedesaan atau kawasan hutan (Sulastiningsih \& Santoso, 2012).

Pengolahan dan pemanfaatan bambu perlu mempertimbangkan karakteristik bambu tersebut. Hal ini karena ada beberapa karakteristik bambu yang berpengaruh pada terbatasnya penggunaan bambu itu sendiri. Untuk meningkatkan pemanfaatan bambu dalam berbagai keperluan diperlukan adanya teknologi pengolahan dan pengawetan (Sunardiyanto, 2012). Beberapa teknologi bambu yang dapat diaplikasikan antara lain pembuatan wood pellet, pembuatan bambu laminasi, pembuatan inti kayu lapis, arang bambu, pulp dan kertas, transportasi dan pariwisata, serta teknologi pengawetan (Arsad, 2015).
Berkaitan dengan kondisi pemanfaatan bambu di Gorontalo banyak terdapat home industry produksi potongan bambu yang digunakan untuk dupa dan tusuk sate. Selain itu, setiap tahunnya di Gorontalo dipastikan memanfaatkan bambu, terutama ketika menghadapi malam pasang lampu. Pemanfaatan dan pemasaran bambu yang luas mengakibatkan pekerja mengalami keslutian dalam proses pemotongan bambu. Hal ini karena proses pemotongan bambu dilakukan secara manual, sehingga membutuhkan waktu dan tenaga yang lebih tinggi. Dampak negatif lain dari proses pemotongan secara manual adalah sangat rentan terjadi kecelakaan kerja.

Kegiatan proses pemotongan bambu dengan menggunakan mesin merupakan cara cepat memotong bambu tanpa menggunakan gergaji yang digerakkan oleh manusia. Mekanisme mesin pemotong bambu memiliki beberapa model diantaranya dengan menggunakan mata gurinda potong. Penggunaan mata gurinda potong lebih memiliki banyak keuntungan ditinjau dari aspek keselamatan dan keefisienannya. Oleh karena itu, salah satu tujuan penelitian ini adalah mengkaji literatur berkaitan dengan mesin dan peralatan yang digunakan untuk memotong bambu. Hasil studi ini diharapkan mampu mejadi dasar untuk menentukan indikator-indikator penting dalam pembuatan mesin pemotong bambu yang efektif dan efisien.

\section{METODE PENELITIAN}

\section{Jenis Penelitian}

Penelitian ini merupakan penelitian analisis kualitatif berkaitan dengan menggunakan pendekatan studi literatur dalam teknik pegumpulan data. Studi literatur ini dilakukan dengan serangkaian kegiatan pengumpulan data, membaca, mencatat, dan mengolah bahan penelitian. Bahanbahan penelitian bersumber dari artikel, buku, jurnal dan sumber lainnya. Adapun sumber kajian pada penelitian ini adalah artikel atau jurnal yang berkaitan dengan mesin pemotong bambu dan sejenisnya.

\section{Indikator Studi Literatur}

Indikator yang dapat dijadikan fokus kajian dalam studi literatur ini adalah sistem kerja alat dan komponen-komponen rancangan alat yang digunakan dalam pembuatan mesin pemotong bambu. 


\section{HASIL DAN PEMBAHASAN}

Pemanfaatan dan peningkatan pemanfaatan bambo di Indonesia, terutama di Gorontalo menuntut para pelaku usaha atau masyarakat untuk meningkatkan produksinya. Peningkatan produksi tentunya berbanding lurus dengan peralatan yang digunakan. Artinya, semakin baik alat yang digunakan maka akan berpengaruh pada peningkatan kualitas dan kuantitas produksi. Sebagaimana diketahui umumnya masyarakat dalam mengolah bambu terutama pada proses pemotongan masih terbatas pada peralatan yang sederhana. Disamping itu, proses pemotongan masih bergantung pada tenaga manusia sehingga rentan terhadap kecelakaan kerja. Oleh karena itu, diperlukan peralatan khusus yang dapat membantu masyarakat dalam pemotogan bambu. Selain sebagai solusi permasalahan di atas, juga dapat mengurangi biaya, waktu, dan tenaga. Dengan demikian, penggunaan mesin dalam proses pemotongan bambu dapat meningkatkan hasil dan mengurangi kecelakaan kerja pada saat pengolahannya.

Di bawah ini terdapat beberapa alat atau mesin yang digunakan dalam proses pengolahan bambu.

\section{Alat Pemotong Bambu Otomatis (Riska, dkk., 2017)}

Alat pemotong bambu otomatis kombinasi mekanik, elektrik, dan software (Gambar 1) merupakan alat pemotong bambu yang dapat diaplikasikan secara manual maupun otomatis. Pemotongan secara manual dapat dilakukan dengan menghidupkan/mematikan gergaji dari saklar, sedangkan pemotongan secara otomatis dilakukan dengan batuan deteksi sensor. Prinsip kerja sensor adalah ketika sensor medeteksi adanya bambu maka gergaji listrik akan menyala, dan sebaliknya.

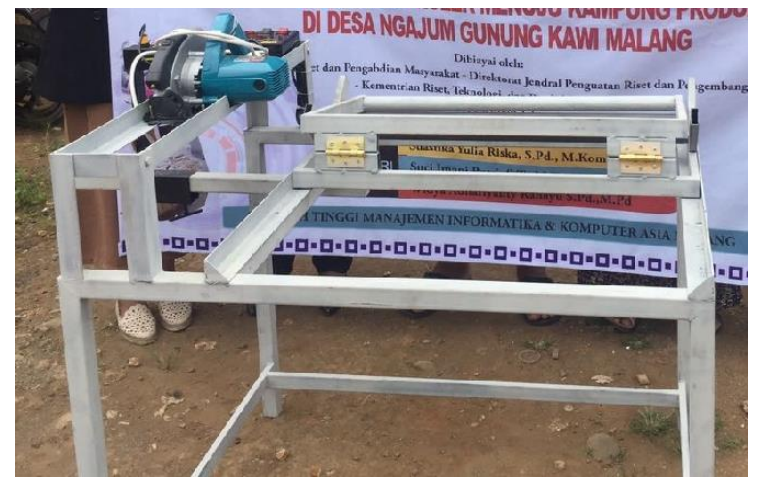

Gambar 1. Alat Pemotong Bambu Otomatis (Riska, dkk., 2017)
Berdasarkan hasil pegujian, produksi pemotongan bambu meningkat dari $25 \mathrm{~kg} / \mathrm{hari}$ menjadi $100 \mathrm{~kg} / \mathrm{hari}$. Peningkatan produksi ini tentunya berimplikasi pada efisiensi waktu yang diperlukan dalam pemotongan bambu. Artinya, alat ini dapat mereduksi waktu dan tenaga untuk meningkatkan produktivitas.

\section{Alat Pemotong Bambu UMKM Alifa Craft (Purba, 2018)}

Pembuatan alat pemotong bambu dimaksudkan untuk mengurangi keluhan sakit dan kecelakaan kerja para pekerja. Pemotongan bambu menggunakan mesin dapat mempengaruhi hasil potongan dimana permukaan potongan rata (lurus) dan permukaan daging bambu tidak kasar. Selain itu, penggunaan mesin pemotong bambu dapat menurukan waktu proses pemotongan sebesar $82,87 \%$. Meskipun demikian, sangat penting dalam perancangan alat/mesin pemotong bambu mempertimbangkan aspek postur tubuh dari para pekerja. Hal ini dimaksudkan untuk menjaga kemudahan dalam pemotogan dan menghindari keletihan, ancaman keseleo, pegal-pegal, atau akibat lain dari posisi alat yang kurang sesuai dengan postur tubuh para pekerja.

\section{Mesin Penyerut Bambu (Rahardjo \& Priama, 2008)}

Mesin ini digunakan sebagai pengiris dan penyerut bambu yang terdiri dari beberapa komponen (Gambar 2), diantaranya: 1) motor penggerak, 2) pulley, 3) poros, 4) rangka, 5) roller, 6) dudukan pisau, dan 7) pegas. Motor yang digunakan pada mesin ini meggunakan motor penggerak Tipe A 09 A-4 dengan putaran poros 142 rpm dan daya 1134 Watt. Adapun jenis pisau yang digunakan pada mesin ini adalah pisau penyayat yang terbuat dari baja karbon. Pisau ini berfungsi sebagai alat pemotong atau pengiris beda kerja (bambu).

Berdasarkan hasil pengujian diperoleh hasil bahwa dimensi benda kerja (bambu) berpengaruh pada produk yang dihasilkan, dimana semakin besar dimensi bambu semakin sedikit pencapaian produksi (batang bambu) per jamnya. Diantara faktor yang dapat dijadikan pertimbangan dalam meghasilkan produk yang baik adalah tingkat kepresisian material input dan perancangannya. 


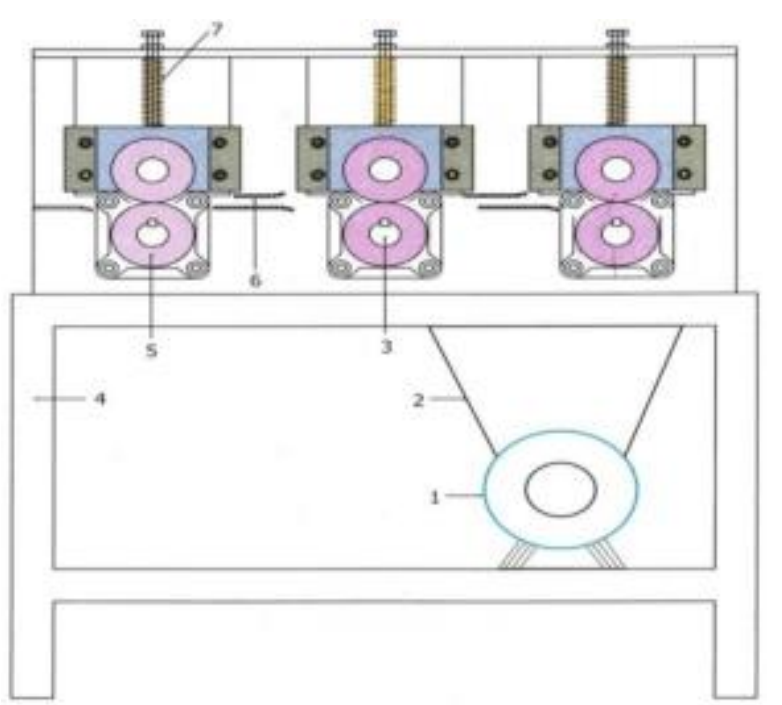

Gambar 2. Mesin Pengiris Bambu (Rahardjo \& Priama, 2008)

\section{Mesin Pemotong Bambu Lidi Tusuk Sate (Ibrahim, dkk., 2019)}

Meskipun alat ini secara spesifik digunakan untuk pemotongan bambu dalam bentuk lidi tusuk sate. Namun, secara desain dan fabrikasi alat ini dapat dijadikan literatur dasar untuk membuat mesin pemotong bambu yang umum, termasuk mesin pemotong bambu multifungsi. Mesin pemotong lidi tusuk sate (Gambar 3) merupakan mesin yang digunakan oleh pengrajin tusuk sate di Lampung Selatan sebagai solusi peningkatan produktivitas. Hal ini karena lidi tusuk sate sebelumnya dipotong dengan cara manual (gergaji tangan) yang pada aplikasinya pekerja merasa tidak nyaman karena harus membugkuk dan melakukan pemutaran benda kerja (bambu). Dampak lain dari pemotongan secara manual ini adalah hasil potongan yang berserabut (tidak rata), patah pada ujung lidi tusuk sate, tidak seragam, dan memerlukan waktu yang lebih lama.

Disamping meja sebagai kerangka utama, alat/mesin ini dilengkapi dengan beberapa komponen penting yaitu tuas jungkat-jungkit, mal ukur, penutup mata pisau, dan tuas pencekam. Tuas jungkat-jungkit berfungsi untuk menggerakkan mata pisau naik turun yang dilengkapi dengan komponenkomponen seperti motor, mata pisau, penutup mata pisau, puli (pulley), v-blet, dan tombol on/off. Mal ukur berfungsi utuk menentukan ukuran lidi tusuk sate yang akan dipotong. Adapun penutup (casing) mata pisau (gurinda) dimaksudkan untuk mengurangi kecelakaan kerja saat pemotongan lidi tusuk sate. Sedangkan tuas pencekam berfungsi untuk mencekam lidi saat pemotongan agar memudahkan pekerja dan hasilnya sesuai ukuran yang diinginkan.

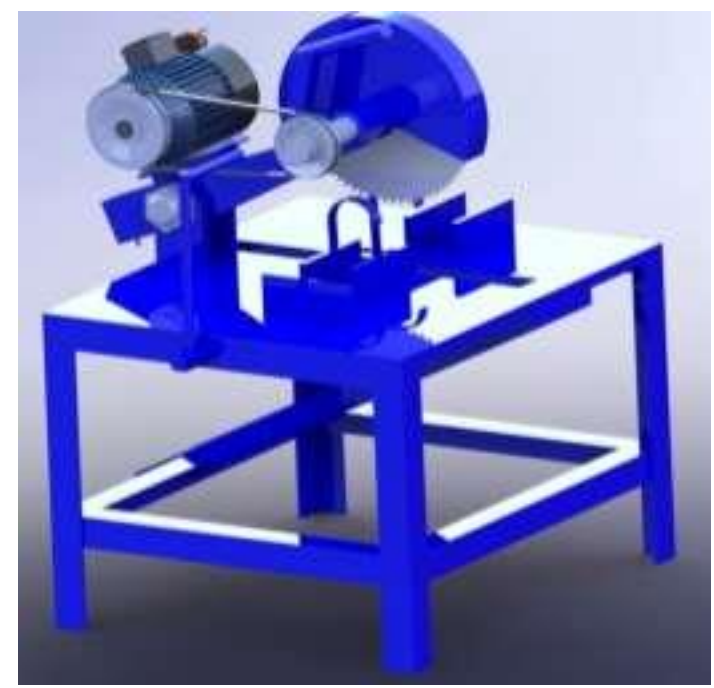

Gambar 3. Mesin Pemotong Lidi Tusuk Sate (Ibrahim, dkk., 2019)

Berdasarkan hasil pengujian diperoleh bahwa mesin ini dapat mereduksi waktu sebanyak $83,33 \%$. Dengan persentase pengurangan waktu operasi tersebut tentu menigkatkan produktivitas, dimana penggunaan gergaji manual dalam pemotongan lidi hanya menghasilkan 60 ikat lidi per jamnya, sementara pemotongan lidi menggunakan mesin mampu menghasilkan 360 ikat lidi per jamnya. Artinya, pemotongan lidi tusuk sate menggunakan mesin dapat meningkatkan hasil sebanyak 6 kali lipat dari pemotongan menggunakan gergaji manual. Jika dalam 1 ikat berisi sebanyak 500 lidi tusuk sate maka dalam 1 jam mampu menghasilkan sebanyak 180000 tusuk sate. Dengan demikian, penggunaan mesin sebagai solusi pemotongan lidi tusuk sate secara manual mampu meningkatkan produktivitas disamping juga lebih ergonomis.

\section{KESIMPULAN}

Berdasarkan uraian di atas dapat disimpulkan sebagai berikut:

1. Mesin pemotong bambu sebagai solusi pemotongan secara manual terbukti dapat meingkatkan produktivitas.

2. Pembuatan mesin pemotong bambu dapat digabungkan dengan teknik kontrol otomasi melalui beberapa aplikasi/software.

3. Kerangka mesin dibuat dengan memperhatikan postur/tinggi badan para pekerja. 
4. Penggunaan mal ukur sangat dianjurkan untuk kesesuaian dan keseragaman benda kerja (bambu) yang dipotong.

5. Diperlukan casing (penutup) mata pisau atau gurinda yang digunakan sebagai alat potong untuk menghindari kecelakaan kerja.

\section{DAFTAR PUSTAKA}

Arhamsyah, 2009, Pegolahan Bambu dan Pemanfaatannya dalam Usaha Pengembangan Industri Kecil Menengah dan Kerajinan, Jurnal Riset Industri Hasil Hutan, Vol. 1, No. 2, hal. 30-35.

Arsad, E., 2015, Teknologi Pengolahan dan Manfaat Bambu, Jurnal Riset Industri Hasil Hutan, Vol. 7, No. 1, hal. 45-52.

Handayani, S., 2009, Arsitektur dan Lingkungan. Bandung: Universitas Pendidikan Indonesia.

Ibrahim, G.A., Hamni, A., \& Budiono, W., 2019, Pembuatan dan Pengujian Mesin Pemotong Tusuk Sate, Jurusan Teknik Mesin, Unila, Lampung

http://ppm.ejournal.id/index.php/pengabdian/ article/download/207/135

Jana, I.M., 2007, Pengolahan Bambu Sebagai Produk Kerajinan ditengah Lesunya Kepariwisataan Di Bali.

Purba, B.N., 2018, Perancangan Alat Pemotong Bambu di UMKM Alifa Craft, Tugas Akhir, Fakultas Teknologi Industri, Universitas Atmajaya Yogyakarta, Yogyakarta https://ejournal.uajy.ac.id/14115/

Rahardjo, S., \& Priama, U., 2008, Rancang Bangun Mesin Penyerut Bambu, Jurusan Teknik Mesin, Universitas Muhammadiyah Jakarta, hal. 45-61, Jakarta https://media.neliti.com/media/publications/2 92163-rancang-bangun-mesin-penyerutbambu-21aae0d0.pdf

Riska, S.Y., Putri, S.I., \& Rahayu, W.A., 2017, Pelatihan Alat Pemotong Bambu Otomatis Berbasis Mikrokontroler menuju Kampung Produktif di Desa Ngajum Gunug Kawi Malang, Jurnal Ilmiah Teknologi Informasi Asia, Vol. 11, No. 2, hal. 154-162.

Sulastiningsih, I.M., 2008, Teknik Pembuatan Bambu Lamina. Penelitian pada Pusat Litbang Keteknikan Kehutanan dan Pengolahan Hasil Hutan. FSRD.

Sulastiningsih, I.M., \& Santoso, A., 2012, Pengaruh Jenis Bambu, Waktu Kempa, dan Perlakuan
Pendahuluan Bilah Bambu terhadap Sifat Papan Bambu Lamina, Jurnal Penelitian Hasil Hutan, Vol. 30, No. 30, hal. 199-207.

Sunardiyanto, E., 2012, Teknologi Kayu Bambu dan Serat, Jurusan Teknologi Industri Pertanian. Fakultas Teknologi Pertanian. Universitas Brawijaya. Malang http://blog.ub.ac.id/ekosunardiyanto/2012/10 /16/tugas-teknologi-kayu-bambu-dan-seratpotensi/

Widyaningrum, A., Hermanto, N.I.S., \& Hardini, P., 2019, Peralatan Teknologi Bambu Laminasi bagi Pengrajin Bambu di Kecamatan Kaliworo Kabupaten Wonosobo Jawa Tengah, Prosiding Seminar Nasional dan Call for Papers: "Pengembangan Sumber Daya Perdesaan dan Kearifan Lokal Berkelanjutan IX, 19-20 November 2019, Purwokerto, hal. 632-641. 